\title{
ASPEK BIOLOGI IKAN SEBELAH (Psettodes erumei) YANG TERTANGKAP DAN DIDARATKAN DI PELABUHAN PERIKANAN PANTAI (PPP) TAWANG KABUPATEN KENDAL
}

\author{
Biological Aspect of Flatfish (Psettodeserumei) which was Caught and Landed in Coastal Fishing Port (PPP) \\ of Tawang, Kendal Regency
}

Leni Barokah, Anhar Solichin*), Djoko Suprapto

Program Studi Manajemen Sumberdaya Perairan, Jurusan Perikanan

Fakultas Perikanan dan Ilmu Kelautan, Universitas Diponegoro

Jl. Prof. Soedarto, SH, Tembalang, Semarang, Jawa Tengah - 50275, Telp/Fax. +6224 7474698

Email : leni_barokah@ymail.com

\begin{abstract}
ABSTRAK
Ikan Sebelah (Psettodes erumei) merupakan ikan demersal yang hidup di dasar perairan. Tujuan dari penelitian ini adalah untuk mengetahui aspek biologi ikan Sebelah di Perairan Kabupaten Kendal. Penelitian ini dilaksanakan pada bulan Mei-Juni 2016. Metode dalam penelitian ini adalah metode deskriptif. Pengambilan sampel menggunakan metode simple random sampling atau acak sederhana. Data primer meliputi panjang berat, tingkat kematangan gonad, dan fekunditas untuk mengetahui aspek biologi ikan Sebelah, sedangkan data sekunder meliputi data produksi ikan Sebelah selama penelitian. Hasil penelitian menunjukan ukuran panjang ikan Sebelah mempunyai kisaran $140 \mathrm{~mm}$ - $310 \mathrm{~mm}$ dan berat dengan kisaran 31 gram - 332 gram, ukuran pertama kali ikan tertangkap ( $\mathrm{L}_{50 \%}$ ) adalah $228 \mathrm{~mm}$. Sifat pertumbuhanya bersifat allometrik positif dengan nilai Kn adalah 1,19. Tingkat kematangan gonad ikan Sebelah jantan didominasi oleh TKG III dan IV, sedangkan tingkat kematangan gonad ikan Sebelah betina didominasi oleh TKG IV. Nilai indeks kematangan gonad terendah pada ikan Sebelah jantan adalah $0,07 \%$ dan nilai IKG tertinggi adalah $1,03 \%$, sedangkan nilai IKG terendah pada ikan Sebelah betina adalah $0,24 \%$ dan nilai IKG tertinggi adalah $4,41 \%$. Fekunditasnya berkisar antara 38.832 - 64.318 butir. Diameter telur terkecil pada TKG IV dan terbesar pada TKG VI. CPUE tertinggi pada sampling minggu ke 1 yaitu sebesar $5.607 \mathrm{~kg} / \mathrm{kapal}$ sedangkan CPUE terendah terjadi pada sampling minggu ke 4 yaitu sebesar $3.623 \mathrm{~kg} / \mathrm{kapal}$.
\end{abstract}

Kata Kunci : Ikan Sebelah (Psettodes erumei), Perairan Kendal, Pola Pertumbuhan.

\section{ABSTRACT}

Flatfish (Psettodeserumei) is kind of demersal fish that lives in seabed. The aimed of this research is to find out the biological aspect of flatfish of Kendal Regency waters. The research was done in May to June of 2016. The method used in this research is descriptive method. In taking the sample, it uses simple random sampling method. The primary data include long weight, gonad maturity level and fecundity to know the biological aspect of flatfish. Secondary data include flatfish production data during research. The result shows the flatfish length is about $140-310 \mathrm{~mm}$ and its weight is about $31-332 \mathrm{gram}$. The length of first caught flatfish (L50\%) is $228 \mathrm{~mm}$. Its nature of growth is allometrikpositif, and its Kn value is 1,19. The gonad maturity level of male flatfishis dominated by TKG III and IV, and the gonad maturity level of female flatfish is dominated by TKG IV. The lowest value of gonad maturity level of male flatfish is 0,07\% and the highest IKG value is 1,03\%, while the lowest IKG value of female flatfish is $0,24 \%$ and the highest IKG value is $4,41 \%$. The fecundity is about $38.832-$ 64.318 egg. The smallest egg diameter is in TKG IV and the biggest is in TKG VI. The highest CPUE of first week sampling is $5.607 \mathrm{~kg} / \mathrm{ship}$, while the lowest CPUE is occurred on the fourth week, i.e. $3.623 \mathrm{~kg} / \mathrm{ship}$.

Keywords:Flatfish (Psettodeserumei), Kendal waters, Growth pattern.

\section{*) Penulis penanggungjawab}

\section{PENDAHULUAN}

Potensi perikanan di Tawang Kabupaten Kendal cukup bagus, potensi tersebut dapat dilihat dari nilai produksi, jumlah dan jenis ikan yang didaratkan di TPI Tawang. Pemanfaatan sumberdaya perikanan tersebut dilakukan secara intensif untuk kepentingan kesejahteraan nelayan Kendal. Kegiatan penangkapan ikan Sebelah yang dilakukan secara terus menerus dan tak terkendali serta penggunaan alat tangkap yang tidak selektif akan mengakibatkan menipisnya stok dan penurunan hasil tangkapan. Pertimbangan ini menjadi dasar perlunya pengkajian tentang aspek biologi dan tingkat pemanfaatan terhadap ikan Sebelah di perairan Kabupaten Kendal.

\footnotetext{
${ }^{(}{ }^{C}$ Copyright by Management of Aquatic Resources (MAQUARES)
} 
Informasi mengenai aspek biologi dan tingkat pemanfaatan dapat digunakan untuk pengelolaan sumberdaya ikan Sebelah demi mewujudkan pemanfaatan ikan Sebelah yang lestari dan berkelanjutan. Pelabuhan Perikanan Pantai Tawang merupakan Pelabuhan yang terletak di Desa Gempolsari, Kecamatan Rowosari, Kabupaten Kendal, Jawa Tengah. Perairan Kendal memiliki potensi perikanan yang cukup besar dan dapat dimanfaatkan oleh masyarakat setempat sebagai sumber pendapatan, misalnya yang dilakukan oleh masyarakat daerah Tawang yang mayoritas menjadi nelayan. Jumlah produksi perikanan di daerah Tawang terus meningkat setiap tahunnya (Mahendra, 2015).

Ikan sebelah di Perairan Kendal merupakan sumberdaya ikan demersal yang penting, sehingga perlu diteliti aspek biologi dan analisis dari hasil tangkapanya guna menunjang pengembangan pemanfaatan sumberdaya ikan Sebelah. Penelitian ini dilakukan untuk mengetahui sumberdaya ikan Sebelah (Psettodes erumei) dilihat dari aspek biologi, yang meliputi faktor kondisi, struktur ukuran, ukuran rata-rata tertangkap $\left(\mathrm{L}_{50 \%}\right)$, dan hubungan panjang berat. Reproduksi meliputi TKG., IKG., fekunditas, ukuran pertama kali matang gonad $\left(\mathrm{Lm}_{50 \%}\right)$, dan diameter telur.

Tujuan dari penelitian ini adalah sebagai berikut :

1. Mengetahui struktur ukuran ikan Sebelah (Psettodes erumei) dan ukuran pertama kali ikan tertangkap $\left(\mathrm{L}_{50 \%}\right)$;

2. Mengetahui sifat pertumbuhan ikan Sebelah meliputi hubungan panjang berat dan faktor kondisi;

3. Mengetahui reproduksi ikan Sebelah meliputi tingkat kematangan gonad (TKG), indeks kematangan gonad (IKG), fekunditas, ukuran pertama kali matang gonad $\left(\mathrm{Lm}_{50 \%}\right)$, dan diameter telur.

Hasil penelitian mengenai aspek biologi ikan Sebelah (Psettodes erumei) yang tertangkap dan didaratkan di Pelabuhan Perikanan Pantai (PPP) Tawang Kabupaten Kendal ini diharapkan mampu menyediakan informasi ilmiah bagi masyarakat khususnya nelayan dan instansi-instansi pemerintah terkait mengenai pengelolaan sumberdaya perikanan yag berkelanjutan.

\section{MATERI DAN METODE PENELITIAN}

\section{A. Materi Penelitian}

Materi yang digunakan dalam penelitian ini adalah ikan Sebelahh (Psettodes erumei) hasil tangkapan nelayan yang didaratkan di Pelabuhan Perikanan Pantai (PPP) Tawang Kabupaten Kendal. Bahan yang digunakan dalam penelitian ini adalah aquadest, pipet tetes dan sedwick rafter.

\section{B. Metode Penelitian}

Metode yang digunakan dalam penelitian ini adalah metode deskriptif. Berdasarkan metode tersebut, penelitian ini menggambarkan secara sistematis, faktual dan akurat mengenai kegiatan perhitungan pendugaan stok ikan Sebelah di perairan Kendal beserta aspek biologinya seperti hubungan panjang-berat, faktor kondisi, ukuran pertama kali tertangkap (L50\%), Tingkat Kematagan Gonad (TKG), Indeks Kematangan Gonad (IKG), ukuran pertama kali saat ikan matang gonad (Lm), dan fekunditas. Teknik pengambilan sampel yang digunakan dalam penelitian ini adalah simple random sampling atau acak sederhana.

Pengambilan sampel dilakukan di PPP Tawang dikarenakan PPP ini mempunyai produksi ikan Sebelah dan merupaka PPP terbesar yang ada di Kabupaten Kendal. Pengambilan ikan contoh dilakukan selama 1 bulan sebanyak 4 kali. Ikan contoh diambil menggunakan metode acak sederhana (simple random sampling), jumlah ikan contoh yang diambil $10 \%$ dari jumlah ikan yang ada tiap sampling. Setiap pengambilan sampel, sampel diambil $10 \%$ dari total individu populasi yang diteliiti untuk pengamatan dan perhitungan TKG dan IKG. (Sugiharto, 2009 dalam Rahman et al., 2013).

\section{Metode Pengambilan Sampel}

Data yang diperoleh meliputi Data Primer dan Data Sekunder adalah sebagai berikut :

1. Data Primer meliputi panjang ikan, berat ikan, tingkat kematangan gonad, dan fekunditas. Pengumpulan data primer dilakukan empat kali selama penelitian.

2. Data Sekunder, meliputi data produksi ikan Sebelah per Minggu.

D. Analisa Data

1. Sifat Pertumbuhan

a. Hubungan Panjang Berat

Menurut Hile (1936) dalam Effendie (1997), menyatakan hubungan antara panjang total ikan dengan beratnya dapat digunakan dengan rumus:

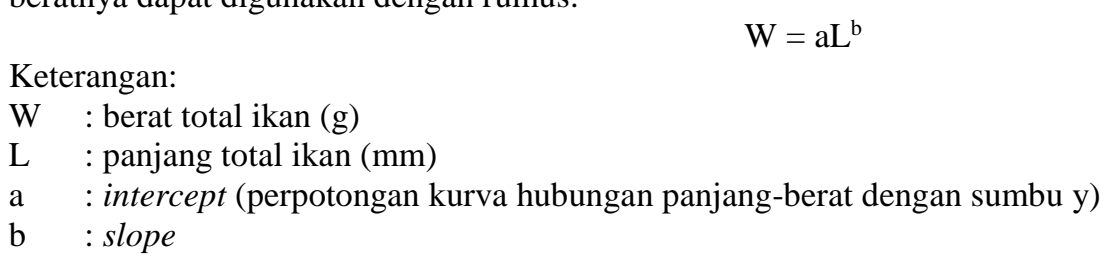


untuk menguji nilai $b=3$ atau $b \neq 3$ dilakukan uji-t (uji parsial), dengan hipotesis:

$\mathrm{H}_{0}: \mathrm{b}=3$, hubungan panjang dengan berat adalah isometrik.

$\mathrm{H}_{1}: \mathrm{b} \neq 3$, hubungan panjang dengan berat adalah allometrik, yaitu:

Allometrik positif, jika $b>3$ (pertambahan berat lebih cepat daripada pertambahan panjang) dan allometrik negatif, jika $b<3$ (pertambahan panjang lebih cepat daripada pertambahan berat).

b. Faktor Kondisi

Menurut Effendie (2002), perhitungan faktor kondisi berdasarkan hubungan panjang berat menggunakan rumus $\mathrm{W}=\mathrm{aL}^{\mathrm{b}}$ maka perhitungan faktor kondisi dapat menggunakan faktor kondisi relatif $(\mathrm{Kn})$ yang dirumuskan:

$$
\mathrm{Kn}=\frac{\mathrm{W}}{\mathrm{aL}^{\mathrm{b}}}
$$

Keteragan: $\mathrm{Kn}$ : faktor kondisi dalam berat total

$\mathrm{W}$ : berat rata-rata ikan $(\mathrm{g})$

$\mathrm{L}$ : panjang rata-rata ikan $(\mathrm{mm})$

a dan $\mathrm{b}:$ konstanta

2. Komposisi Ukuran Hasil Tangkapan

a. Struktur Ukuran

Penentuan struktur ukuran panjang hasil tagkapan ikan menggunakan data panjang total ikan Sebelah yang tertangkap dan diturunkan di PPP Tawang Kabupaten Kendal.

b. Ukuran Pertama Kali Ikan Tertangkap ( $\left.\mathrm{L}_{50 \%}\right)$

Menurut Saputra (2009), ukuran pertama kali ikan tertangkap didapatkan dari metode kurva logistik baku. Nilai tersebut didapatkan dengan cara memplotkan persentase frekuensi komulatif ikan dengan ukuran panjang. Titik potong antara kurva dengan 50\% frekuensi komulatif adalah panjang saat 50\%. Ukuran ikan yang layak tangkap dapat ditentukan dengan terlebih dahulu mencari nilai $\mathrm{L}_{\infty}$, dengan persamaan sebagai berikut:

$$
\mathrm{L}_{\infty}=\frac{\mathrm{Lmax}}{0,95}
$$

Dimana:

$\mathrm{L}_{\infty} \quad=$ Panjang infinity

Nilai $\mathrm{L}_{50 \%}$ dinyatakan sudah cukup besar dan layak ditangkap jika $\mathrm{L}_{50 \%}>1 / 2 \mathrm{~L}_{\infty}$

3. Aspek Reproduksi

a. Tingkat Kematangan Gonad (TKG)

Jenis kelamin diduga berdasarkan pengamatan gonad ikan contoh. Dasar yang dipakai untuk menetukan TKG adalah antara lain dengan pengamatan ciri-ciri morfologi secara mikroskopis, yaitu bentuk, ukuran panjang, berat, warrna dan perkembangan isi goonad. Penentua TKG secara morfologi mengacu kepada TKG ikan modifikasi dari Kesteven.

b. Indeks Kematangan Gonad (IKG)

Menurut Effendie (2002), IKG dihitung dengan membandingkan bobot gonad dengan bobot tubuh ikan gonad tersebut dikali $100 \%$. Dengan rumus sebagai berikut:

$$
\mathrm{IKG}=\frac{\mathrm{B} E}{\mathrm{Br}} \times 100 \%
$$

Keterangan:

$\mathrm{IKG}=$ Indeks Kematangan Gonad

$\mathrm{Bg}=$ Berat gonad ikan sebelah (gram)

$\mathrm{Bt}=$ Berat tubuh ikan Sebelah bersama gonad (gram)

c. Ukuran Pertama Kali Matang Gonad (Lm)

Ukuran pertama kali matang gonad diperoleh dengan mencari nilai Lm dengan memplotkan persentase komulatif ikan matang gonad dengan ukuran panjang tubuh.

d. Fekunditas

Fekunditas adalah jumlah telur masak sebelum dikeluarkan pada saat ikan memijah. Fekunditas hanya dihitung pada ikan betina yang memiliki TKG IV, V dan VI.

Fekunditas dapat dihitung menggunakan rumus sebagai berikut (Effendie 1997):

$$
\mathrm{F}=\frac{G \times V x X}{\varphi}
$$

Keteragan:

$$
\mathrm{F}=\text { Fekunditas } \mathrm{G}=\text { Berat gonad }(\mathrm{gr}) \quad \mathrm{V}=\mathrm{Isi} \text { pengenceran }(\mathrm{cc}) \quad \mathrm{X}=\text { Jumlah telur tiap cc }
$$

4. Catch Per Unit Effort (CPUE)

Nilai CPUE merupakan perbandingan antara hasil tangkapan per satuan upaya penangkapan yang dirumuskan sebagai berikut:

CPUE' $=\frac{\text { catch }}{\text { effort }}$

${ }^{\text {C }}$ Copyright by Management of Aquatic Resources (MAQUARES) 
Keterangan:

Catch : hasil tangkapan ikan (kg) Effort : upaya penangkapan ikan (trip)

Nilai CPUE digunakan untuk melihat perkembangan stok ikan di suatu perairan. Data hasil tangkapan dan trip penangkapan diperoleh selama penelitian.

5. Diameter Telur

Diameter telur diukur menggunakan mikroskop elektrik yang sudah diketahui ukuran diameter telur ikan yang akan diamati. Telur yang sudah dihitung fekunditasnya kemudian diukur diameternya di bawah mikroskop dengan pembesar 40 kali dengan bantuan mikrometer okuler yang telah ditera sebelumnya. Telur diamati secara acak dari subgonad. Selanjutnya diameter telur dianalisis dalam bentuk diagram.

\section{HASIL DAN PEMBAHASAN}

A. Hasil

a. Deskripsi Lokasi Penelitian

Menurut Dinas Kelautan dan Perikanan Provinsi Jawa Tengah (2013), secara administratif Tempat Pelelangan Ikan Tawang terletak di Dukuh Tawang, Desa Gempolsewu, Kecamatan Rowosari, Kabupaten Kendal dan secara geografis terletak diantara $6^{0} 55^{\prime} 0,3^{\prime \prime}$ LS dan $110^{\circ} 02^{\prime} 49^{\prime \prime}$ BT. Batas-batas wilayah Gempolsewu adalah sebelah utara dengan Laut Jawa, sebelah timur dengan Desa Sendang Sikucingg, sebelah selatan dengan Desa Rowosari, dan sebelah barat dengan Kabupaten Batang. Di Kabupaten Kendal terdapat 4 Tempat Pelelangan Ikan (TPI) yang beroperasi yaitu TPI Tawang, TPI Sendang Sikucing, TPI Tanggul Malang, dan TPI Bandengan. PPP Tawang merupakan PPP terbesar yang ada di Kabupaten Kendal dan PPP ini mempunyai produksi ikan Sebelah terbesar.

\section{b. Struktur Ukuran}

1. Modus Ukuran Panjang dan Berat Ikan Sebelah

Pengamatan ukuran panjang dan berat ikan Sebelah berguna untuk mengetahui komposisi ukuran, hubungan panjang berat, dan faktor kondisi. Jumlah sampel untuk pengukuran panjang dan berat ikan sebanyak 226 ekor dengan kisaran ukuran panjang $140 \mathrm{~mm}-310 \mathrm{~mm}$ dan berat dengan kisaran $31 \mathrm{gram}-$ 332 gram. Kisaran panjang ikan Sebelah tersaji pada Gambar 1.

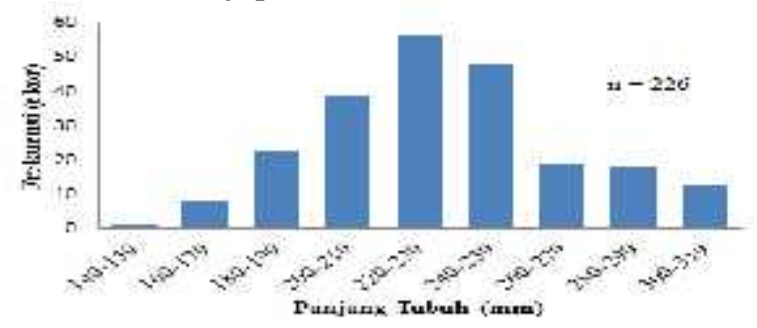

Gambar 1. Kisaran Panjang Ikan Sebelah (Psettodes erumei)

Berdasarkan Gambar 1 diatas, maka dapat diketahui bahwa jumlah ikan Sebelah yang banyak tertangkap memiliki kisaran panjang 220-239 sebanyak 57 ekor.

2. Pola atau Sifat Pertumbuhan

Hasil perhitungan panjang dan berat menggunakan analisis regresi linier tersaji pada Gambar 2.

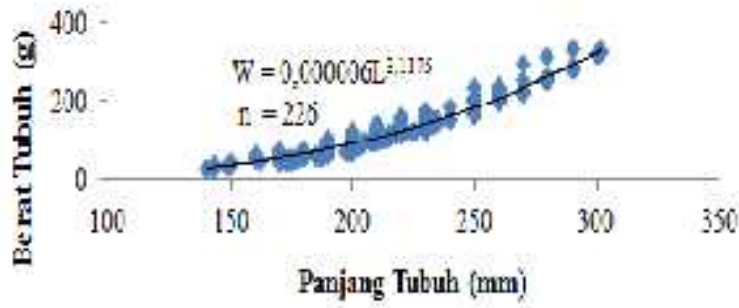

Gambar 2. Grafik Hubungan Panjang dan Berat Ikan Sebelah

Berdasarkan hasil analisis hubungan panjang berat, diperoleh nilai a sebesar 0,000006 dan nilai $\mathrm{b}$ sebesar 3,1175 setelah dilakukan uji t didapatkan $b>3$. Nilai faktor kondisi ikan Sebelah yang diperoleh selama penelitian sebesar 1,19 degan rata-rata pajang 225,94 mm dan rata-rata berat 156,33 gram.

3. Ukuran Pertama Kali Ikan Tertangkap $\left(\mathrm{L}_{50 \%}\right)$

Penentuan ukuran pertama kali tertangkap ikan Sebelah tersaji pada Gambar 3. 


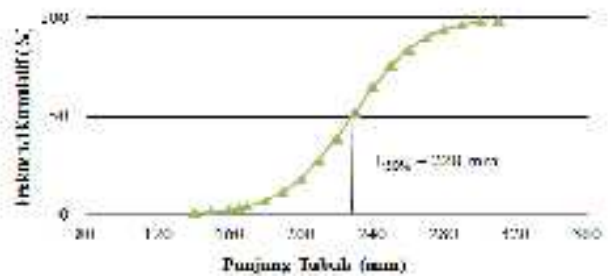

Gambar 3. Ukuran Pertama Kali Tertangkap (L50\%) Ikan Sebelah

Berdasarkan Gambar 3 diatas, dapat diketahui bahwa ukuran pertama kali tertangkap (L50\%) ikan Sebelah selama penelitian adalah $228 \mathrm{~mm}$.

4. Ukuran Pertama Kali Matang Gonad (Lm)

Berdasarkan hasil penelitian grafik ukuran pertama kali matang gonad ( $\mathrm{L}_{50 \%}$ ) dapat dilihat pada Gambar

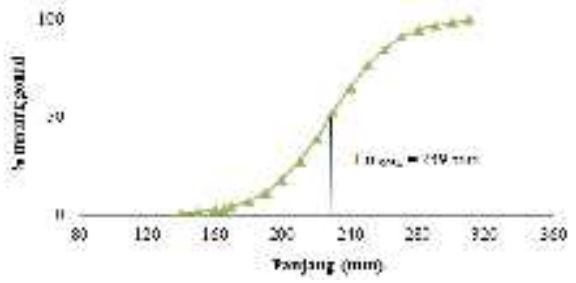

Gambar 4. Ukuran Pertama Kali Matang Gonad (Lm) Ikan Sebelah Jantan dan Betina

Ukuran pertama kali matang gonad dari grafik diatas yaitu $239 \mathrm{~mm}$, jika dikaitkan dengan ukuran ratarata tertangkap sebesar $228 \mathrm{~mm}$ dapat disimpulkan bahwa banyak ikan Sebelah yang tertangkap sebelum matang gonad. Ikan Sebelah tersebut sebenarnya masih bisa berkembang dan melakukan pemijahan tetapi sesudah ditangkap sebelum masa tersebut sehingga dapat mengancam kelestarianya.

c. Aspek Reproduksi

1. Tingkat Kematangan Gonad

Sampel ikan Sebelah jantan dan betina yang diamati tingkat kematangan gonadnya selama penelitian berjumlah masing-masing 60 dan 40 ekor. Pengamatan tingkat kematangan gonad dilakukan melalui pengamatan secara morfologi. Pengamatan tingkat kematangan gonad ikan Sebelah jantan dan betina. Tabel 1. Tingkat Kematangan Gonad (TKG) Ikan Sebelah

\begin{tabular}{|c|c|c|c|c|c|c|c|c|}
\hline \multirow{2}{*}{ No } & \multirow{2}{*}{$\begin{array}{l}\text { Jenis } \\
\text { Kelamin }\end{array}$} & \multirow{2}{*}{$\begin{array}{l}\text { Jumlah } \\
\text { (Ekor) }\end{array}$} & \multicolumn{6}{|c|}{ Tingkat Kematangan Gonad } \\
\hline & & & I & II & III & IV & $\mathrm{V}$ & VI \\
\hline 1 & Jantan & 60 & 34 & 8 & 17 & 1 & - & - \\
\hline 2 & Betina & 40 & 11 & 4 & 4 & 9 & 10 & 2 \\
\hline
\end{tabular}

Berdasarkan tabel di atas, jumlah ikan Sebelah yang paling banyak berada pada TKG I yaitu 34 ekor dan terendah pada TKG IV sebesar 1 ekor. Sedangkan pada ikan Sebelah betina terbanyak pada TKG I yaitu 11 ekor dan terendah pada TKG VI sebesar 2 ekor. Hal ini berarti ikan Sebelah yang tertangkap dan didaratkan di PPP Tawang Kabupaten Kendal di dominasi oleh ikan yang belum matang gonad dan masih dalam masa pertumbuhan. Hal ini tidak baik karena berpengaruh pada pertumbuhan dan persediaan stok ikan Sebelah berikutnya. Pengamatan TKG ikan berbagai daerah dan waktu sampling dapat digunakan untuk memprediksi waktu pemijahan dan daerah pemijahan sehingga dapat disusun konsep pegelolaan terkait dengan daerah dan waktu pemijahan.

2. Indeks Kematangan Ggonad

Perhitungan nilai indeks kematangan gonad ikan Sebelah jantan dan betina dapat tersaji pada tabel 2 dan 3.

Tabel2. Nilai Indeks Kematangan Gonad yang Terkecil dan Terbesar Ikan Sebelah Jantan

\begin{tabular}{cccc}
\hline No & Panjang Ikan $(\mathbf{m m})$ & Berat Ikan $(\mathbf{g})$ & IKG $(\%)$ \\
\hline 1 & 210 & 135 & 0,07 \\
2 & 220 & 136 & 1,03 \\
\hline
\end{tabular}

Tabel 3. Nilai Indeks Kematangan Gonad yang Terkecil dan Terbesar Ikan Sebelah Betina

\begin{tabular}{cccc}
\hline No & Panjang Ikan $(\mathbf{m m})$ & Berat Ikan $(\mathbf{g})$ & IKG $(\boldsymbol{\%})$ \\
\hline 1 & 229 & 127 & 0,24 \\
2 & 250 & 202 & 4,41 \\
\hline
\end{tabular}

Nilai IKG terbesar pada ikan Sebelah jantan adalah 1,03\%, sedangkan nilai IKG sedangkan pada ikan Sebelah betina adalah 4,41\%. Ini menunjukan bahwa nilai IKG ikan Sebelah jantan lebih kecil dibandingkan

(C) Copyright by Management of Aquatic Resources (MAQUARES) 
dengan nilai IKG ikan Sebelah Betina. Indeks kematangan gonad akan meningkat nilainya dan mencapai batas maksimum pada saat akan terjadi pemijahan.

3. Fekunditas

Fekunditas adalah jumlah telur ikan sebelum berlangsungnya pemijahan. Hasil pengamatan TKG ikan betina berjumlah 21 ekor yang telah matang gonad. Dari 21 ekor yang dihitung fekunditasnya didapatkan nilai terendah sebanyak 38.832 butir dan nilai tertinggi sebanyak 64.318 butir. Fekunditas mempunyai hubungan dengan umur, panjang dan berat tubuh. Hubungan fekunditas dengan panjang dan berat ikan Sebelah disajikan pada Gambar 4.
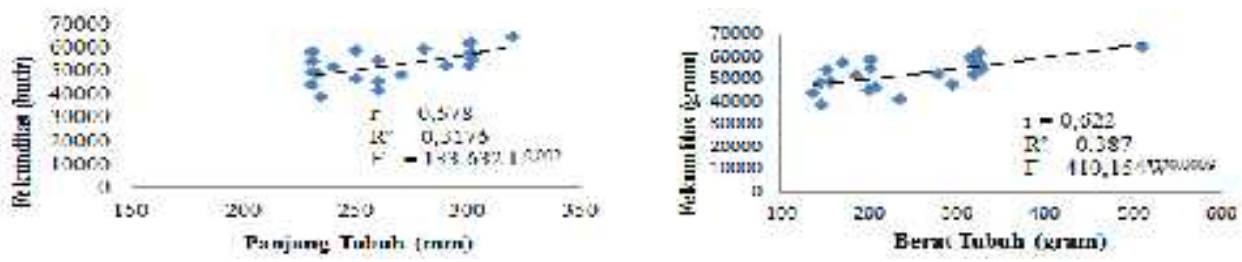

Gambar 4. Grafik Hubungan Panjang Tubuh dengan Fekunditas dan Berat Tubuh Dengan Fekunditas Ikan Sebelah

Berdasarkan grafik di atas diperoleh koefisien korelasi hubungan antara fekunditas dengan panjang tubuh ikan dan berat tubuh ikan sebesar 0,578 dan 0,622. Sehingga, dapat diartikan terdapat hubungan yang kuat antara fekunditas dengan berat ataupun panjang ikan.

4. CPUE (Catch Per Unit Effort)

Data CPUE yang telah diperoleh setiap 1 minggu sekali selama penelitian mengalami fluktuasi. CPUE tertinggi pada sampling minggu ke 1 yaitu sebesar $5.607 \mathrm{~kg} / \mathrm{kapal}$ sedangkan CPUE terendah terjadi pada sampling minggu ke 4 yaitu sebesar $3.623 \mathrm{~kg} / \mathrm{kapal}$. Produksi ikan Sebelah berdasarkan data primer selama penelitian tersaji pada Gambar 5.

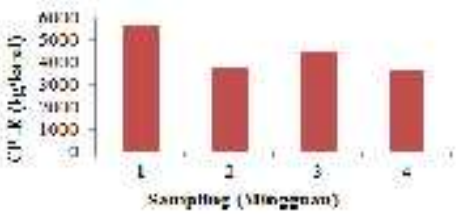

Gambar 5. Perkembangan Produksi Ikan Sebelah Selama Penelitian

5. Diameter Telur

Hasil pengukuran diameter telur TKG IV, V, VI sebanyak 21 ekor sampel ikan dan tersaji pada Gambar

6.
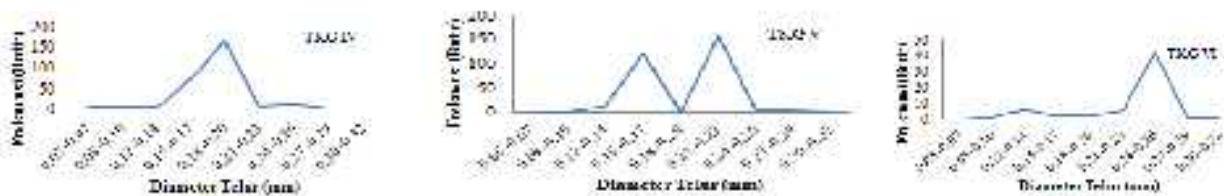

Gambar 6. Distribusi Diameter Telur Ikan Sebelah pada Tingkat Kematangan Gonad IV,V, dan VI

\section{B. Pembahasan}

\section{a. Pola Pertumbuhan}

Hasil analisa hubungan panjang dan berat ikan Sebelah selama penelitian didapatkan nilai a sebesar 0,000006 dan nilai $b$ sebesar 3,1175 dengan peersamaan $\mathrm{W}=0,000006 \mathrm{~L}^{3,1175}$. Nilai $\mathrm{b}$ yang dihasilkan yaitu 3,1175 yang berarti $b>3$ maka pertumbuhan berat lebih cepat dari panjangnya.

Faktor kondisi ikan Sebelah yang didaratkan di PPP Tawang Kabupaten Kendal selama penelitian diperoleh nilai Kn sebesar 1,19. Sedangkan menurut penelitian Redjeki (2002), nilai Kn ikan Sebelah di perairan Jepara yaitu 1,0054 yang artinya bahwa ikan Sebelah yang didaratkan di PPP Tawang lebih montok dibandingkan dengan ikan Sebelah di Jepara. Faktor yang menentukan harga Kn dikemukakan oleh Effendie (2002) yaitu ketersediaan makanan, umur, jenis kelamin, dan kematangan gonad.

Menurut Purnomo (1997), panjang Psettodes erumei dapat mencapai 500mm, umumnya 200-400mm. Hasil dari penelitian didapat berat ikan Sebelah terkecil yaitu 31 gram dengan panjang ikan 140mm. Ukuran rata-rata tertangkap ( $\mathrm{L}_{50 \%}$ ) untuk ikan Sebelah $228 \mathrm{~mm}$. Ukuran rata-rata tertangkap (L50\%) dapat digunakan untuk membantu upaya pengelolaan, karena dapat digunakan untuk mengetahui ikan yang tertangkap sudah layak atau belum. Untuk mengetahui apakah ukuran rata-rata ikan yang tertangkap sudah layak tangkap atau belum dapat diketahui dengan membandingkan dengan 1/2 L $\infty$ (Sparre, P dan Venema, 1999). 
Dari perhitungan didapatkan $\mathrm{L} \infty$ untuk ikan Sebelah adalah $568,42 \mathrm{~mm}$ sehingga setengah dari $\mathrm{L} \infty$ 284,21 mm. Ukuran rata-rata tertangkap $228 \mathrm{~mm}$, karena $\mathrm{L}_{50}<1 / 2 \mathrm{~L} \infty$ sehingga ikan Sebelah yang tertangkap masih terlalu kecil. Kelayakan ukuran tangkap ini erat kaitannya dengan kelestarian ikan tersebut. Jika ukuran yang tertangkap belum layak tangkap maka hal tersebut akan memicu terjadinya growth overfishing. Adapun faktor lain yang mempengaruhi kecilnya ukuran yang tertangkap yaitu ukuran mata jaring yang digunakan sudah dimodifikasi menjadi lebih kecil oleh para nelayan dengan harapan jumlah ikan yang terjaring akan lebih banyak. Ukuran mata jaring cantrang yang seharusnya berkisar antara 2-7 inci tetapi yang digunakan 1/2 inci $(12,7 \mathrm{~mm})$ ukuran pada kantong, sedangkan nilai SF didapatkan 21,88 . Oleh karena itu perlu adanya pelebaran pada ukuran mata jaring Cantrang agar ikan Sebelah yang masih berukuran kecil tidak tertangkap.

\section{b. Aspek Reproduksi}

Tingkat kematangan gonad diperlukan untuk menentukan atau mengetahui perbandingan antara ikan yang masak gonadnya dengan yang belum dari stok yang ada dalam perairan, ukuran atau umur ikan pertama kali masak gonad dan mengetahui ikan yang sudah memijah atau belum. Dari 100 ekor sampel ikan didapatkan yang telah matang gonad sebanyak 12ekor pada betina dan jantan 1 ekor, sedangkan ikan Sebelah yang belum matang gonad berjumlah lebih banyak yaitu 28 ekor ikan pada betina dan 59 ekor pada ikan jantan. Banyaknya jumlah TKG I dan II (belum matang gonad) terjadi karena penelitian dilakukan pada bulan Mei-Juni yang merupakan bulan sebelum musim memijah. Seperti dikemukakan oleh Pradhan (1962), bahwa kematangan gonad dan bulan pemijahan ikan Sebelah terjadi di bulan Agustus hingga Desember. Widodo (1991) mengemukakan bahwa, pemijahan dilakukan sebelum musim barat karena dimanfaatkan oleh ikan Sebelah untuk memulihkan energi karena musim barat menyebabkan arus di Laut Jawa bergerak sangat kuat, kondisi ini menyebabkan ikan akan membutuhkan energi guna menyesuaikan diri dengan lingkungannya. Dari hasil penelitian juga didapatkan jumlah jantan 60 ekor lebih banyak dibandingkan jumlah betina 40 ekor. Menurut Pradhan (1962), jumlah persentase jantan akan naik sebelum musim berrtelur, yaitu di bulan Agustus.

Perubahan yang terjadi dalam gonad secara kuantitatif dapat diketahui dari Indeks Kematangan Gonad (IKG). Pada ikan jantan diperoleh nilai IKG terendah 0,07\% dan IKG tertinggi 1,03\%. Menurut Effendie (1979), bahwa berat gonad akan mencapai maksimum sesaat ikan memijah, kemudian berat gonad akan menurun dengan cepat selama pemijahan sedang berlangsung sampai selesai. Pulungan, et al., (1994) dalam Yustina dan Arnentis (2002) menyatakan bahwa umumnya ikan yang hidup di perairan tropis dapat memijah sepanjang tahun dengan nilai IKG yang lebih kecil pada saat ikan tersebut matang gonad.

Kemampuan reproduksi sangat erat kaitannya dengan jumlah telur yang dihasilkan (fekunditas). Hal ini berpengaruh terhadap jumlah anakan yang diproduksi. Fekunditas adalah jumlah telur ikan betina sebelum dikeluarkan pada waktu akan memijah. Fekunditas mempunyai keterkaitan dengan umur, panjang atau berat individu dan spesies ikan. Fekunditas ikan Sebelah pada kisaran panjang total 230-320 mm dengan berat 169510 gr berjumlah 38.832 hingga 64.318 butir. Perbedaan fekunditas tersebut disebabkan adanya variasi ukuran panjang dan berat pada ikan. Koefisien korelasi kedua persamaan garis adalah sebesar 0,578 pada panjang dan 0,622 pada berat. Persamaan hubungan fekunditas dengan berat adalah $F=410,154 \mathrm{~W}^{0,0009}$ dan persamaan hubungan fekunditas dengan panjang adalah $\mathrm{F}=133,632 \mathrm{~L}^{0,002}$ Djuhanda (1981) dalam Yustina dan Arnentis (2002), berpendapat bahwa besar kecilnya fekunditas dipengaruhi oleh makanan, ukuran ikan, dan kondisi lingkungan.

Ukuran ikan saat pertama kali matang gonad $\left(\mathrm{Lm}_{50 \%}\right)$ penting diketahui terutama kaitannya dengan pengelolaan. Untuk menghitung ukuran pertama kali matang gonad data yang diperlukan yaitu panjang ikan, jumlah sampel ikan yang dikumpulkan dan jumlah ikan yang matang gonad. Saputra (2009) menyatakan bahwa data tersebut idealnya dikumpulkan dalam rentang waktu yang cukup panjang (1 tahun) dan atau meliputi wilayah perairan yang dapat mewakili distribusi ikan yang menjadi objek penelitian. $\mathrm{Lm}_{50 \%}$ didapatkan dari memplotkan persentase komulatif ikan matang gonad dengan ukuran panjang tubuh. Hasil dari grafik yang dibuat diperoleh titik potong sebesar $239 \mathrm{~mm}$. Hasil ukuran rata-rata tertangkap sebesar $228 \mathrm{~mm}$ menunjukan bahwa ikan Sebelah yang seharusnya masih dapat memijah tidak berkesempatan pada fase tersebut, hal ini dapat mengancam kelestarian dari ikan Sebelah.

Sebaran diameter ikan Sebelah pada TKG IV menyebar pada kisaran diameter 0,05-0,32 mm dan terbanyak pada diameter $0,19 \mathrm{~mm}$, kemudian yang paling sedikit jumlahnya pada diameter $0,23 \mathrm{~mm}$. Pada TKG V kisaran diameter 0,05-0,32 $\mathrm{mm}$ dan terbanyak pada diameter $0,21 \mathrm{~mm}$, kemudian yang paling sedikit jumlahnya pada diameter 0,29 $\mathrm{mm}$. Pada TKG VI kisaran diameter 0,05-0,32 $\mathrm{mm}$ dan terbanyak pada diameter $0,25 \mathrm{~mm}$, kemudian yang paling sedikit jumlahnya pada diameter $0,32 \mathrm{~mm}$. Terlihat ada kecenderungan semakin tinggi kematangan gonad, maka diameter telur juga semakin besar. (modus bergerak kekanan).

Effendie (1997) menyatakan bahwa semakin berkembang gonad maka semakin besar pula garis tengah telurnya sebagai hasil dari pengendapan kuning telur dan pembentukan butir-butir minyak.

\section{c. CPUE (Catch Per Unit Effort)}

Berdasarkan data CPUE yang diperoleh selama penelitian, CPUE tertinggi pada sampling minggu ke 1 yaitu sebesar $5.607 \mathrm{~kg} / \mathrm{kapal}$ sedangkan CPUE terendah terjadi pada sampling minggu ke 4 yaitu sebesar 3.623 $\mathrm{kg} / \mathrm{kapal}$. Nilai dari CPUE menggambarkan tingkat produktivitas dari upaya penangkapan (effort). Nilai CPUE yang berfluktuatif selama penelitian terjadi penambahan dan pengurangan jumlah upaya penangkapan. Cahyani

\footnotetext{
${ }^{\circledR}$ Copyright by Management of Aquatic Resources (MAQUARES)
} 
et al.,(2013) menyatakan bahwa nilai CPUE semakin tinggi menunjukan tingkat produktivitas alat tangkap yang digunakan semakin tinggi pula. Jika dibandingkan dengan upaya tangkap, maka peningkatan upaya tangkap justru menurunkan hasil tangkapan. Hal ini menunjukan bahwa tidak selalu penambahan alat tangkap akan menaikkan produksi.

\section{KESIMPULAN}

Struktur ukuran ikan Sebelah yang banyak tertangkap berada pada kisaran panjang $140 \mathrm{~mm}-310 \mathrm{~mm}$, dan rata-rata ikan Sebelah yang tertangkap adalah $228 \mathrm{~mm}$, lebih kecil dari $1 / 2 \mathrm{~L} \propto$, ini berarti bahwa ikan Sebelah yang tertangkap oleh nelayan masih terlalu kecil. Persamaan hubungan panjang berat ikan Sebelah dan pertumbuhanya bersifat allometrik positif. Berdasarkan penelitian yang dilakukan bahwa, Tingkat kematangan gonad ikan Sebelah jantan didominasi oleh TKG III dan IV, sedangkan tingkat kematangan gonad ikan Sebelah betina didominasi oleh TKG IV. Hal ini menunjukan bahwa, tingkat kematangan gonad ikan Sebelah jantan maupun betina didominasi oleh ikan yang belum matang gonad, Ukuran pertama kali matang gonad (Lm 50\%) sebesar $239 \mathrm{~mm}$ dan Semakin tinggi kematangan gonad, maka diameter telur juga semakin besar (modus bergerak ke kanan).

\section{UCAPAN TERIMAKASIH}

UcapanterimakasihditujukankepadaDr. Ir. Bambang Sulardiono, M.Si.,Dra. NiniekWidyorini, MS., Churun Ain, S.Pi., M.Si.,Dr. Ir. Pujiono Wahyu P., MS., yang telah memberikan masukan, kritik dan saran yang sangat berarti bagi penulis. KepadaDinas Kelautan dan Perikanan Kabupaten Kendal dan Pegawai Pelabuhan Perikanan Pantai (PPP) Tawang Kabupaten Kendal yang telah membantu dan memberikan informasi.

\section{DAFTAR PUSTAKA}

Dinas Kelautan dan Perikanan Jawa Tengah. 2013. PPP Tawang. http://diskanlutjateng.go.id/2013/microsite/ppp-tawang/profil. (20 Juli 2016)

Effendi, M. I,. 1979. Metode Biologi Perikanan. Yayasan Dewi Sri, Bogor. 2002. Biologi Perikanan. Yayasan Pustaka Nusatama. Yogyakarta. $163 \mathrm{hlm}$.

Mahendra, Feldi. Fitri, Aristi Dian Purnama. Asriyanto. 2015. Analisis Hasil Tangkapan Arad Modifikasi (Modifiied Small Bottom Trawl) Di, Perairan PPP Tawang Kendal Jawa Tengah. Journal Of Fisheries Resources Utilization Management and Technology Volume 4 Nomor 1 Tahun 2015, Hlm 60-69.

Pradhan, M.J. 1962. Observation On The Matury and Spawning Of Psettodes erumei (Scheinder). Taraporevela Marine Biological Research Station, Bombay.

Redjeki, Sri. 2002. Biologi Reproduksi Ikan Sebelah (Psettodes erumei) Di Perairan Jepara. Undip Press. Semarang

Saputra, S. W. 2009. Dinamika Populasi Ikan Berbasis Riset. Universitas Diponegoro. Semarang. $203 \mathrm{hlm}$.

Unnus, F. 2010. Analisis Fekunditas Dan Diameter Telur Ikan Malalugis Biru (Decapterus Macarellus Cuvier, 1833) Di Perairan Kabupaten Banggai Kepulauan, Propinsi Sulawesi Tengah. J. Ilmu Kelautan dan Perikanan. 20(1) : 37-43 